\title{
Relocation of the 10 March 2011 Yingjiang, China, earthquake sequence and its tectonic implications*
}

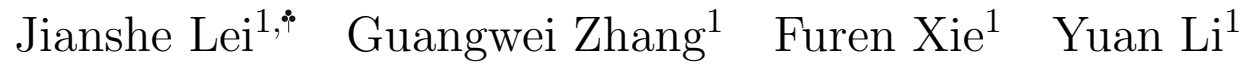 \\ Youjin $\mathrm{Su}^{2}$ Lifang $\mathrm{Liu}^{2}$ Honghu $\mathrm{Ma}^{2}$ and Junwei Zhang ${ }^{2}$ \\ ${ }^{1}$ Key Laboratory of Crustal Dynamics, Institute of Crustal Dynamics, China Earthquake \\ Administration, Beijing 100085, China \\ ${ }^{2}$ Earthquake Administration of Yunnan Province, Kunming 650224, China
}

\begin{abstract}
An earthquake with $M_{\mathrm{S}} 5.8$ occurred on 10 March 2011 in Yingjiang county, western Yunnan, China. This earthquake caused 25 deaths and over 250 injuries. In order to better understand the seismotectonics in the region, we collected the arrival time data from the Yunnan seismic observational bulletins during 1 January to 25 March 2011, and precisely hand-picked the arrival times from high-quality seismograms that were recorded by the temporary seismic stations deployed by our Institute of Crustal Dynamics, China Earthquake Administration. Using these arrival times, we relocated all the earthquakes including the Yingjiang mainshock and its aftershocks using the double-difference relocation algorithm. Our results show that the relocated earthquakes dominantly occurred along the ENE direction and formed an upside-down bow-shaped structure in depth. It is also observed that after the Yingjiang mainshock, some aftershocks extended toward the SSE over about $10 \mathrm{~km}$. These results may indicate that the Yingjiang mainshock ruptured a conjugate fault system consisting of the ENE trending Da Yingjiang fault and a SSE trending blind fault. Such structural features could contribute to severely seismic hazards during the moderate-size Yingjiang earthquake.
\end{abstract}

Key words: Yingjiang earthquake; relocation; double-difference algorithm; Da Yingjiang fault CLC number: P315.3 Document code: A

\section{Introduction}

The Yunnan province, southwestern China, is situated on the southeast margin of the Tibetan plateau. In the region there occurred many strong earthquakes (China Earthquake Administration, 2005), and existed many active faults (Figure 1; Deng et al., 2002) and an active Tengchong volcano (Lei et al., 2009). To the west, on the Indo-Myanmar boundary some intermediate-depth earthquakes formed a clear WadatiBenioff seismic zone down to $\sim 180 \mathrm{~km}$ depth (Engdahl et al., 1998). These geophysical phenomena

\footnotetext{
* Received 30 September 2011; accepted in revised form 12 December 2011; published 10 February 2012.

* Corresponding author. e-mail: jshlei_cj@hotmail.com

(c) The Seismological Society of China, Institute of Geophysics, China Earthquake Administration, and Springer-Verlag Berlin Heidelberg 2012
}

have been attracting many geoscientists to conduct investigations using various techniques (e.g., Tapponnier et al., 1990; Wang and Burchfiel, 1997; Yin and Harrison, 2000; Wang and Huangfu, 2004; Zhao et al., 2006; Lei et al., 2009). On 10 March 2011 an earthquake with $M_{\mathrm{S}} 5.8$ rocked the area, which is located about $3 \mathrm{~km}$ away from the Yingjiang county, western Yunnan, China. A recent study demonstrated that the Yingjiang earthquake could be closely related to fluids contained in the upwelling flow under the Tengchong volcano caused by the deep subduction of the Indian slab (Lei et al., 2012). Till 25 March 2011, the Yingjiang mainshock generated over 2900 aftershocks (Figures 1 and 2), among which there were eight $M>4.0$ and two $M>5.0$ earthquakes. The mainshock caused 25 deaths, over 250 injuries and considerable economic damages. Several institutions, such as Earthquake Administration of Yunnan Province, China Seismic Networks Center, 
Institute of Geophysics, China Earthquake Administration (CEA), United States Geological Survey (USGS), carried out investigations of source parameters of the Yingjiang mainshock, but there existed differences between them in details. These differences could be closely related to the poor density and azimuthal coverage of seismic stations used.

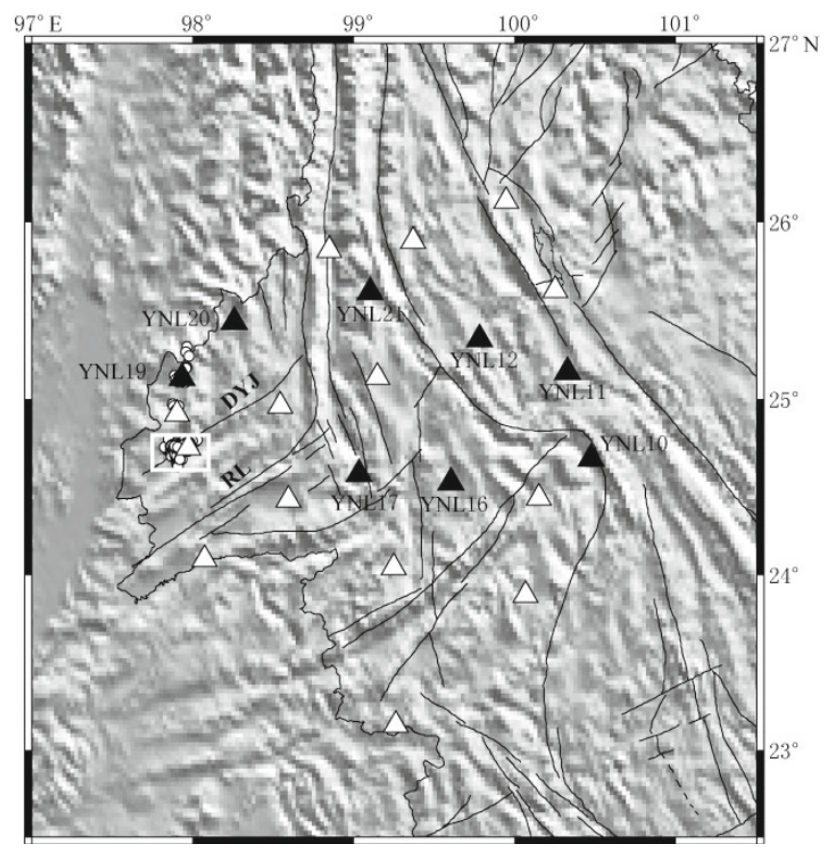

Figure 1 Map illustrating seismic stations used. White triangles denote the Yunnan network, while black triangles denote the temporary network deployed between May 2010 and July 2011 by our Institute of Crustal Dynamics, CEA. White dots denote the 2011 Yingjiang sequence. The white square shows the Yingjiang sequence area in Figures 2, 5-7. Some traces mark the active faults (Deng et al., 2002) in the region. DYJ, the Da Yingjiang fault; RL, the Ruili fault.

Our Institute of Crustal Dynamics, CEA, deployed 21 temporary seismic stations (hereafter we call our temporary network) in the Yunnan region during May 2010 and July 2011 to detect deep structure of the crust and upper mantle around the Tengchong volcano. All these stations recorded the aftershock sequence of the Yingjiang mainshock. Among them, eight stations are relatively close to the Yingjiang mainshock. In particular, there are two stations that were deployed north of the Da Yingjiang fault, which are significantly complementary to the Yunnan temporary and permanent seismic network (hereafter call the Yunnan network) that is only located to the east of the Da Yingjiang fault (Figure 1). Thus, such a well-defined distribution of our temporary seismic stations provides us an opportunity
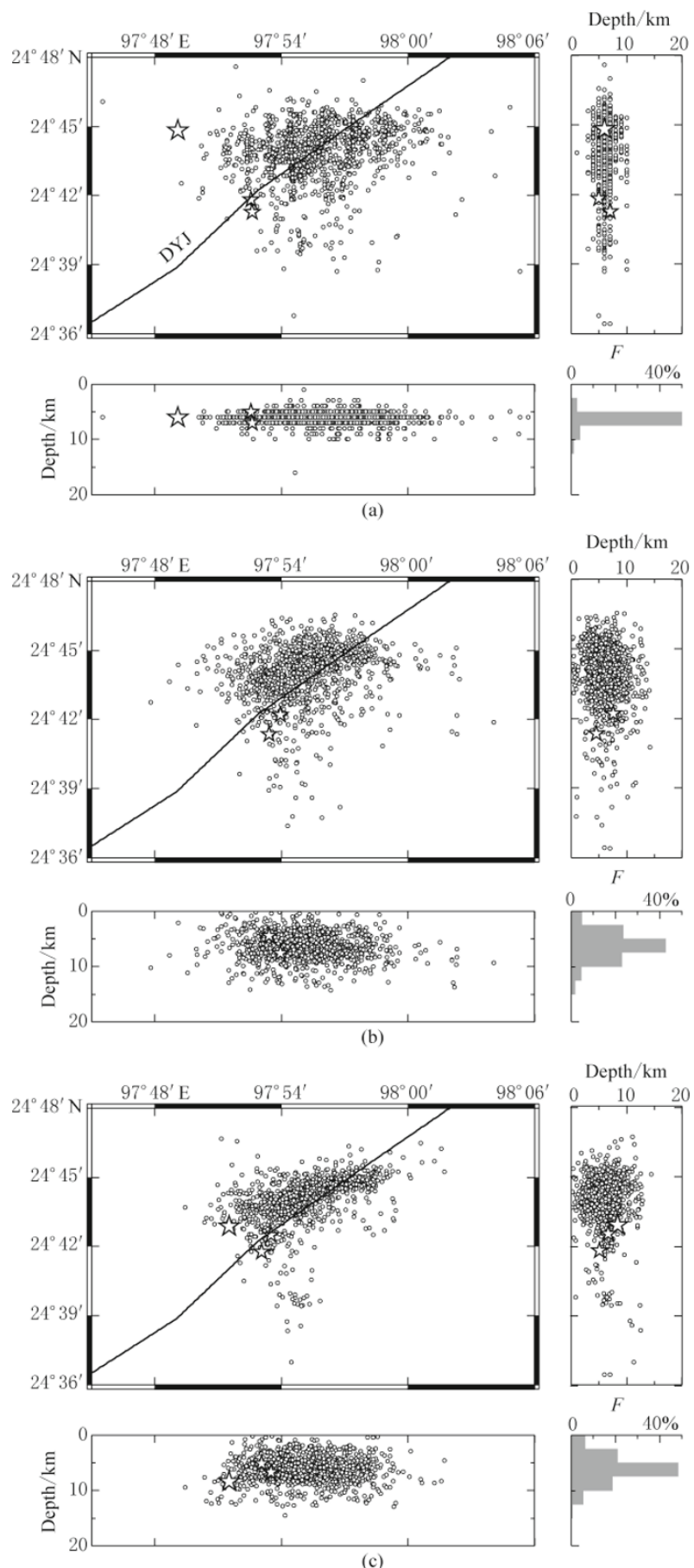

Figure 2 (a) Enlarged map showing the 2011 Yingjiang sequence (solid circles) from the Yunnan observational bulletins. Stars denote the 2011 Yingjiang mainshock and two earthquakes with magnitude larger than 4.0. The solid curve denotes the Da Yingjiang fault (DYJ). (b) The same as (a) but for the relocated Yingjiang sequence only using the Yunnan network. (c) The same as (b) but for adding our temporary network. The right-bottom figure in (a)-(c) shows the distribution of the earthquake sub-frequency $(F)$ with depth. 
to get better relocations of the Yingjiang mainshock and its aftershocks, because combination of our temporary network with the Yunnan network can form a much better coverage of the seismic stations around the Da Yingjiang fault (Figure 1). We used the data set from the combined network to relocate the Yingjiang mainshock and its aftershocks. Our results provide some new insights into the seismotectonics and the nature of seismic hazards in the region.

\section{Data and method}

In this study we collected the arrival time data from two parts: one is the Yunnan seismic observational bulletins, while the other is hand-picked from highquality digital seismic waveforms recorded by our temporary network. The Yunnan digital permanent seismic network has been operated since 2001, but we only collected $12867 \mathrm{P}$-wave and $13254 \mathrm{~S}$-wave arrival time data from 2935 local earthquakes during 1 January to 25 March 2011. Using this Yunnan earthquake catalogue, we cut over 50000 seismograms recorded by our temporary network. Figure 3 shows an example for seismograms from the $2011 M_{\mathrm{S}} 5.8$ Yingjiang mainshock. For small earthquakes $(M<0.8)$, the $\mathrm{P}$-wave and S-wave onsets are usually blurred due to the noise. After our picking, we obtained $4121 \mathrm{P}$-wave and $3460 \mathrm{~S}$-wave arrival times from 1400 events. In this work, we only used the data from the seismic stations to the west of $101^{\circ} \mathrm{E}$. The $1-\mathrm{D}$ velocity model (Figure 4 ) derived from $\mathrm{Hu}$ et al. (1986) and Zhang et al. (2005) was adopted to calculate the theoretical travel times. We removed the arrival time data having travel time residuals larger than 5.0 sec. We chose the $\mathrm{P}$-wave arrival time data with the epicentral distance less than $280 \mathrm{~km}$ and S-wave arrival time data less than $250 \mathrm{~km}$. Finally, we obtained a data set including $10801 \mathrm{P}$-wave and $9846 \mathrm{~S}$-wave arrival times from 1400 earthquakes. Figures 1 and $2 \mathrm{a}$ show the distribution of seismic stations and Yingjiang earthquakes used. It can be seen that the seismic stations have a good azimuthal coverage around the Da Yingjiang fault, and local earthquakes are scattered in the horizontal direction and their focal depths are focused at around $6 \mathrm{~km}$.

We used the double-difference location algorithm (Waldhauser and Ellsworth, 2000) to relocate the Yingjiang mainshock and its aftershocks. The main idea of the method is as follows. It is assumed that two events are very close and the distance between events is much shorter than that from event to station, thus the rays from these two events are approximately the same, and the $1-\mathrm{D}$ velocity model adopted may not have much

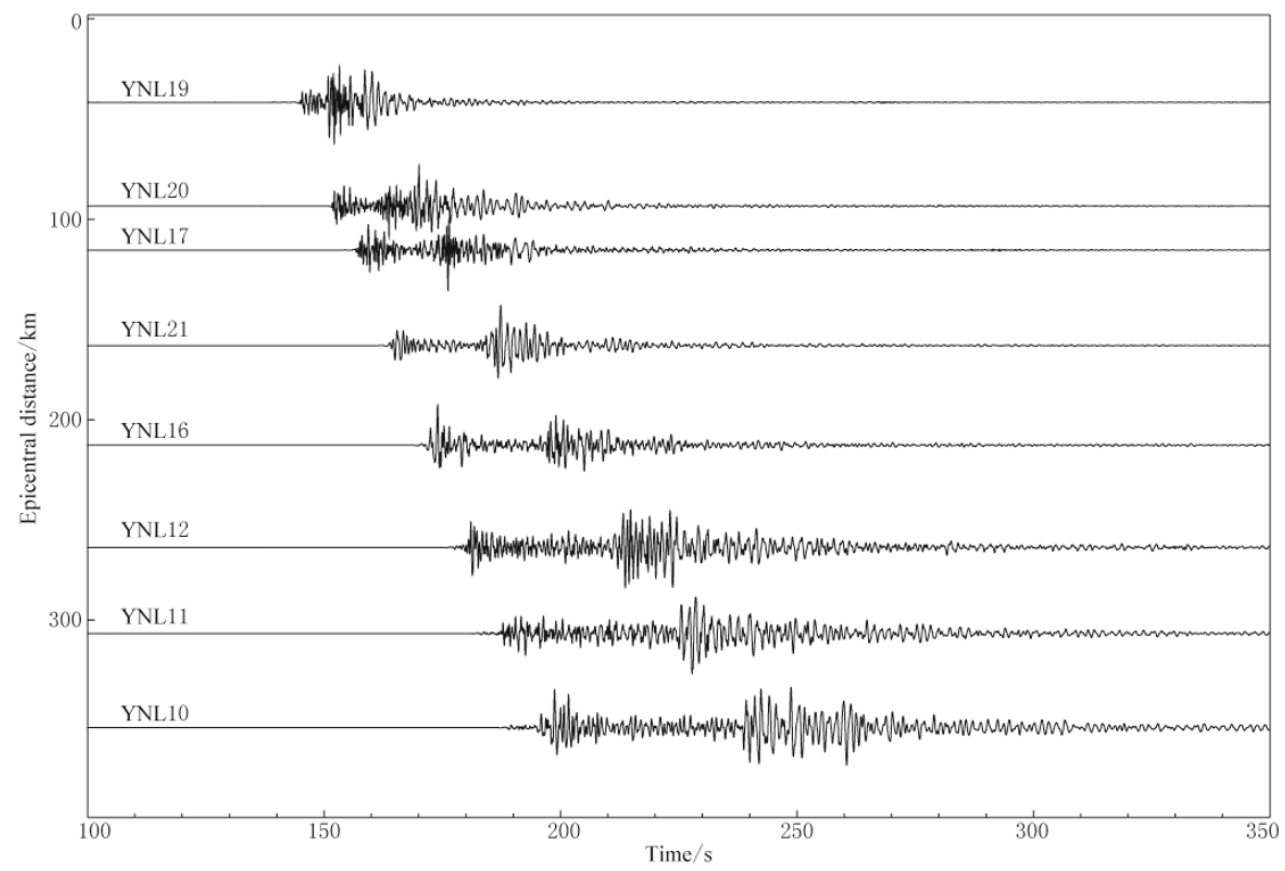

Figure 3 An example showing seismograms recorded at our temporary network from the 10 March $M_{\mathrm{S}} 5.8$ Yingjiang mainshock. The letters denote the names of seismic stations. The vertical axis is the epicentral distance in $\mathrm{km}$ from the Yingjiang mainshock to the seismic station, while the horizontal axis is the time in sec from cutting the seismograms. 


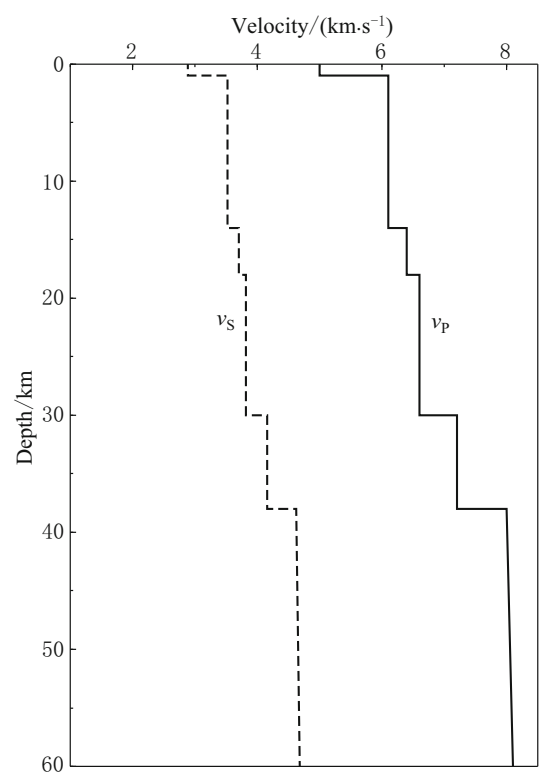

Figure 4 The 1-D velocity models used in the present study. The $v_{\mathrm{P}}$ model (solid line) is summarized from previous studies (Hu et al., 1986; Zhang et al., 2005), while the $v_{\mathrm{S}}$ model (dashed line) is inferred from the velocity ratio $v_{\mathrm{P}} / v_{\mathrm{S}}=1.76$ (Wang et al., 2010).

effect on the travel times. Therefore, the doubledifference travel time residuals could be attributable to the uncertainties of the relative locations of these two events. This method has become very popular in precise earthquake location in the world including Chinese mainland, and it has been demonstrated to be a powerful tool to better understand some parameters of active faults using small earthquakes around the faults (e.g., Yang et al., 2003; Li et al., 2007; Mishra et al., 2008; $\mathrm{Yu}$ et al., 2010; Zhang et al., 2011). For details of the methodology, see Waldhauser and Ellsworth (2000).

\section{Results and analyses}

Combining the arrival times from the Yunnan network and our temporary network, 1148 hypocentral parameters of the Yingjiang sequence have been precisely determined using the double-difference location algorithm (Figures 2c and 5). These results have been significantly improved over the source parameters collected from the Yunnan observational bulletins (Figure $2 \mathrm{a}$ ), and revealed some major features of the Yingjiang seismicity. Most of small earthquakes occurred at $\sim 2-9$ $\mathrm{km}$ depth (Figure 5). The seismicity is predominantly oriented in the ENE direction of the Da Yingjiang fault as shown in map view (Figure 2c), and the seismicity zone becomes gradually narrower and narrower from the west to the east (Figures 5b-5d). Furthermore, the distribution of the earthquake hypocenters forms an upside-down bowl-shaped structure in depth (Figure 5a). In addition, a small number of earthquakes occurred along the SSE direction (Figures 2c and 5b). These observations may suggest that the rupture propagation of the Yingjiang mainshock is not only confined to the ENE trending Da Yingjiang fault, but it also propagates along a blind SSE trending fault.

In order to further understand the rupturing processes of the Da Yingjiang fault, we divided the earthquake period of 1 January to 25 March 2011 into six
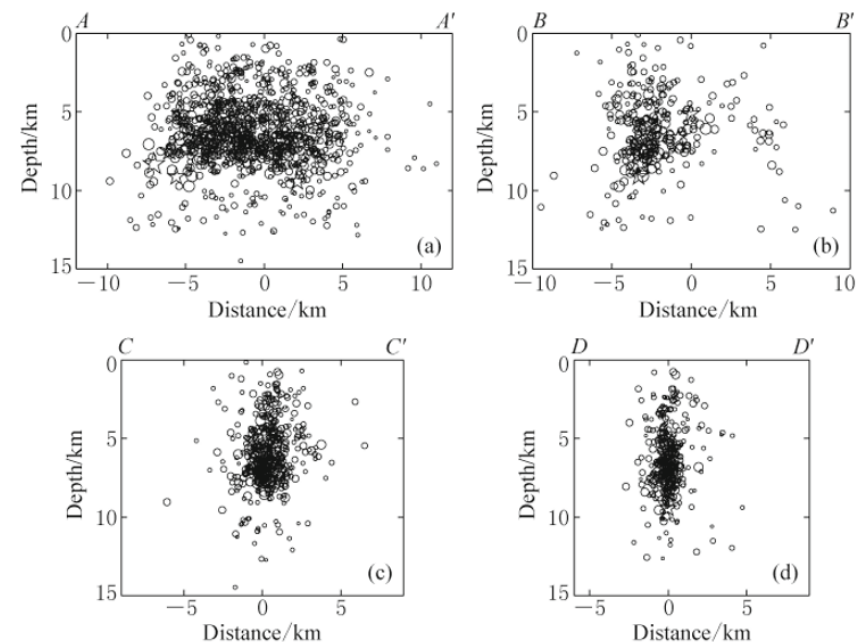

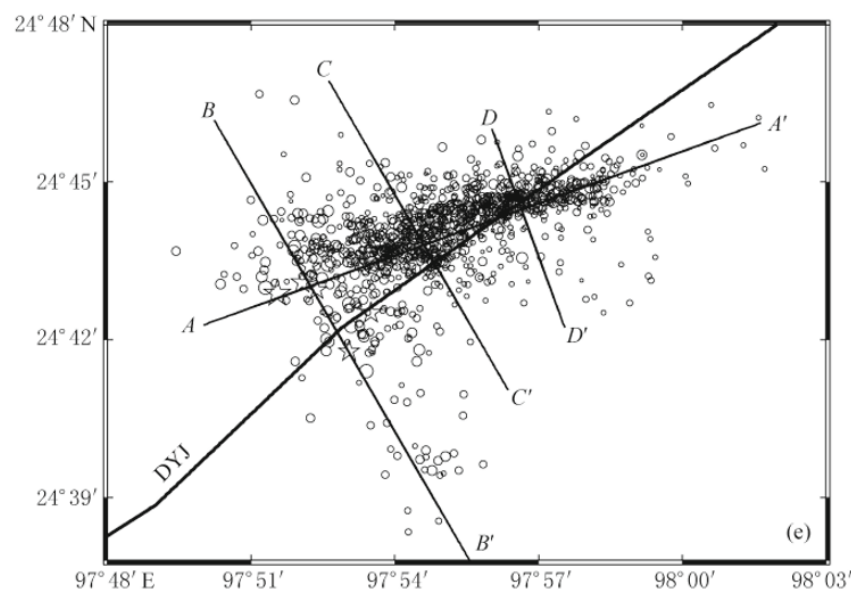

Figure 5 Vertical cross sections of the earthquake sequence along the Da Yingjiang (DYJ) fault (a) and approximately perpendicular to the DYJ fault (b-d) from the west to the east. No vertical exaggerations in (a)-(d). (e) shows locations of vertical cross sections. 
periods: 1-2 January, 3-31 January, 1-3 February, 4 February-9 March, 10-12 March and 13-25 March (Figure 6). It can be clearly seen that in 1-2 January 2011 small earthquakes extended eastward in map view and concentrated upward in depth (Figure 6a). At the following three periods from 3 January to 9 March, it is also found that small earthquakes continued to extend eastward over 6-8 $\mathrm{km}$ in map view but deepened in depth (Figures 6b-6d). After the 10 March $2011 M_{\mathrm{S}} 5.8$ Yingjiang mainshock, most of the aftershocks further extended eastward and deepened, but some of them moved along the SSE direction (Figures 6e and 6f), where existed two $M>4.0$ earthquakes (Figure 6e), which is quite different from the seismicity before the Yingjiang mainshock. These results indicate that the Yingjiang mainshock may have ruptured a conjugate fault system having two different orientations, the ENE trending Da Yingjiang fault and a SSE trending blind fault, which may explain why the Yingjiang mainshock caused such damages as the 25 deaths and over 250 injuries. One more example is that the 2001 Bhuj earthquake also ruptured a conjugate fault system, which resulted in significant loss in the Kutch basin of the western India (Mishra et al., 2008).

In order to demonstrate the reliability of the earthquake locations determined in the present study, we show their relative standard errors in the latitude, longitude and depth directions (Figure 7). It is clearly seen that the errors of all redetermined earthquake locations are smaller than $2.0 \mathrm{~km}$, among which there are 681 earthquakes having the errors less than $1.0 \mathrm{~km}$ in three directions. Furthermore, the errors of the earthquake locations in the central portion of the cluster are much smaller than those on the margins. These results suggest that major structural features of the earthquake locations inferred in our present study are robust in our understanding the fault activity.
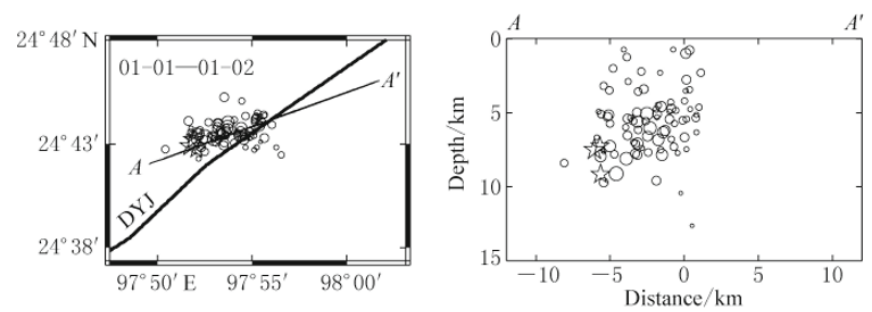

(a)
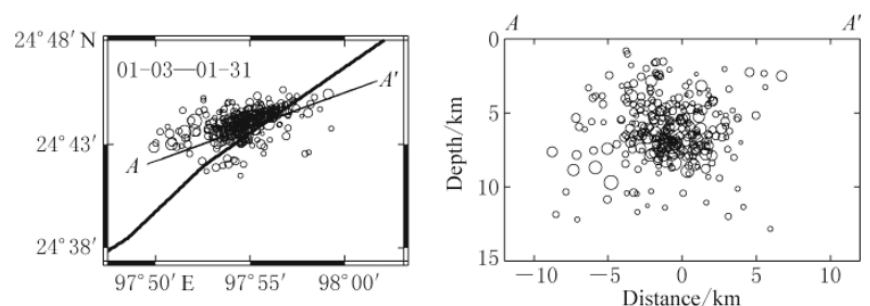

(b)
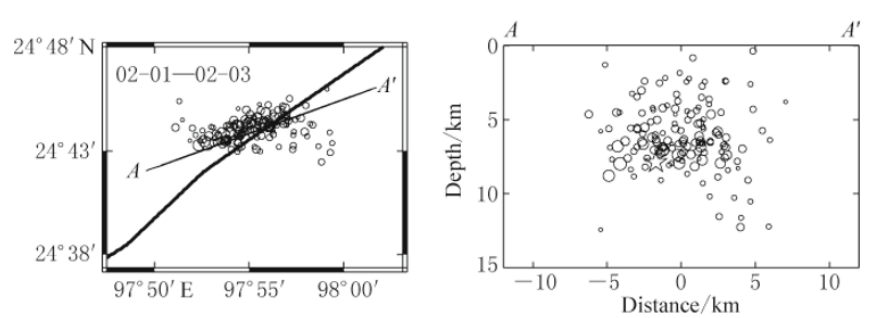

(c)
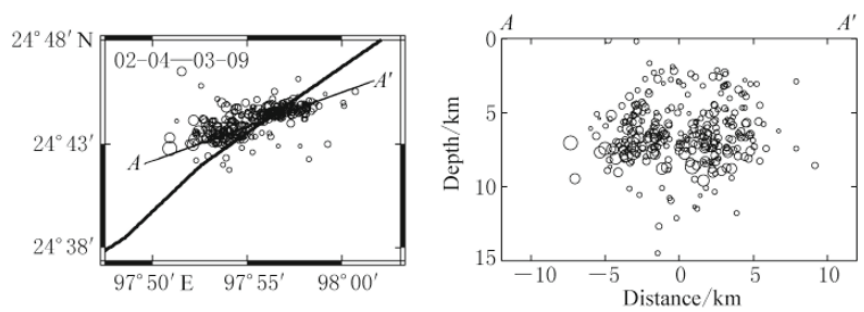

(d)
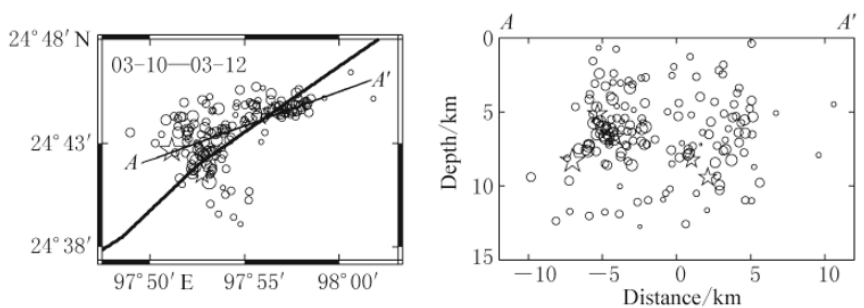

(e)
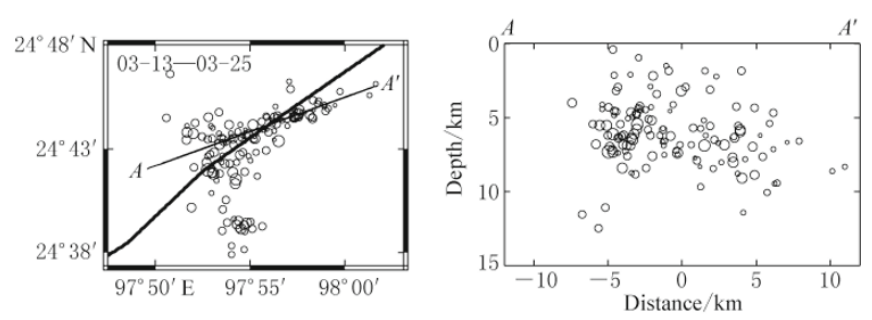

(f)

Figure 6 Spatial migrations of the Yingjiang sequence (solid circles) with time. Left panels show the results in map view, while right panels show the results along the vertical cross section $A A^{\prime}$. Stars denote the earthquakes with magnitude larger than 4.0. The thick line denotes the Da Yingjiang fault (DYJ), while the thin line denotes the location of the vertical cross section $A A^{\prime}$. No vertical exaggerations in right panels. The period of earthquakes is shown on the upper-left corner. 

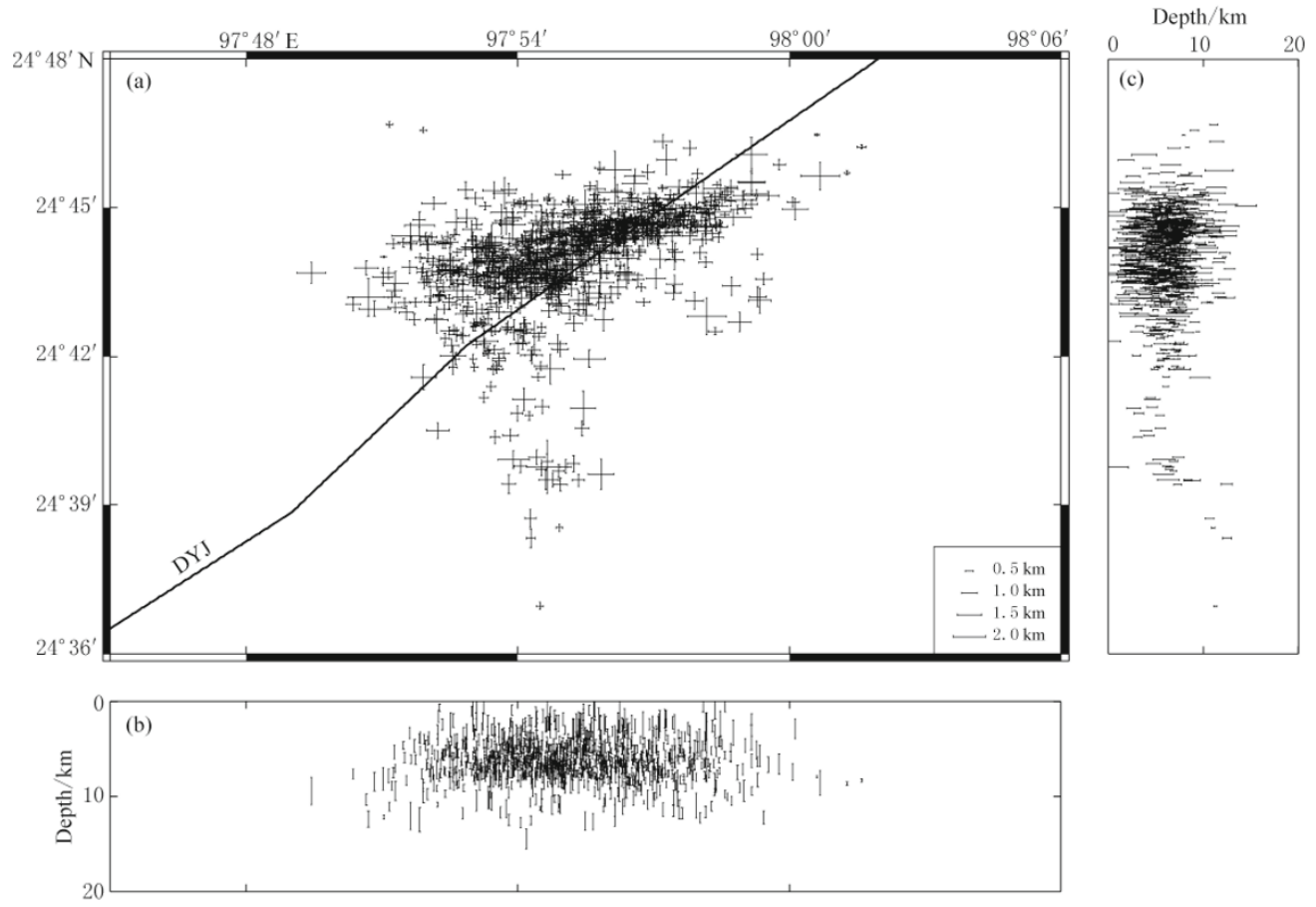

Figure 7 Distribution of relative standard errors of 1148 determined earthquake locations along the latitude and longitude (a) and depth ( $\mathrm{b}-\mathrm{c}$ ) directions. Horizontal and vertical bars in (a) denote the errors along the longitude and latitude directions, respectively, while the bars in (b)-(c) denote the errors in depth. The scale for the error is shown on the right-bottom corner of (a). DYJ, the Da Yingjiang fault.

\section{Discussion}

\subsection{Effect of our temporary network}

In order to reduce the uncertain effect of the 1-D velocity model used in this study, we chose the seismic stations distributed in a relatively small region west of $101^{\circ} \mathrm{E}$. In the region there are 14 seismic stations from the Yunnan network and eight temporary seismic stations from our temporary network (Figure 1). To better understand the effect of the temporary seismic stations on the relocation of the earthquake hypocenters around the Da Yingjiang fault, we conducted one more relocation inversion only using the 14 seismic stations from the Yunnan network (Figure 2b).

Comparing these two results inferred from the Yunnan network and the combined network, it is found that there are some similarities between them. The distribution of small earthquakes is in approximate ENE direction and most of their focal depths are above $9 \mathrm{~km}$ (Figures 2b and 2c). However, there are also some differences between them in details. Only using the Yunnan network, there are 1100 earthquakes that can be relocated and the Yingjiang mainshock was not determined. In addition, the relocated earthquakes show a relatively scattered distribution in both horizontal and vertical di- rections (Figure $2 \mathrm{~b}$ ). When adding the data set from the temporary seismic stations, 1148 earthquakes including the Yingjiang mainshock can be relocated. Moreover, these relocated earthquakes show a much narrower and clearer seismic zone in map view. Most of small earthquakes extended along the ENE direction, while some were along a SSE direction (Figure 2c). These improved results may be closely related to the reasonable coverage of the seismic stations used (Figure 1).

In addition, if the seismic stations used are located on one side of the epicenters, the earthquake locations need the correction for the bias of the earthquake cluster toward the station side, which has been demonstrated by a number of numerical tests in the Tangshan fault zone of North China (Zhang, 2010). However, in the present study we generally have a good azimuthal coverage of seismic stations around the epicenters (Figure 1 ), thus the results obtained in the present study do not require corrections. Moreover, there is one station right above the epicenters, which could be much helpful to determine focal depths.

\subsection{Comparison with previous studies}

After the Yingjiang earthquake, Fang et al. (2011) once conducted the relocation of the Yingjiang earthquake sequence, and they adopted the absolute and rel- 
ative relocation methods using the data set from the Yunnan and Sichuan networks. Most of these seismic stations have large spacing and are concentrated on the eastern portion of the Da Yingjiang fault. In order to improve the azimuthal coverage of the seismic stations around the Yingjiang mainshock, they added one seismic station (MYI) in the Myanmar region. Their results show a similar distribution of small earthquakes but that the focal depth of the Yingjiang mainshock is about $13.4 \mathrm{~km}$.

In the present study, we used the data from the 22 seismic stations in the study region (Figure 1), which is much more than those used by Fang et al. (2011) in the same region. These 22 stations have a significant improvement over previous studies (e.g., Fang et al., 2011) in station density and azimuthal coverage. In particular, we added two temporary seismic stations to the north of the Da Yingjiang fault, which may provide a better constraint on the horizontal location of the Yingjiang mainshock to better determine its focal depth of $8.3 \mathrm{~km}$. Most of focal depths of small earthquakes are better constrained to $2-9 \mathrm{~km}$, although some extended down to $13 \mathrm{~km}$ (Figures 2c and 5). These results suggest that our temporary network may play an important role in determining the earthquake parameters of the Yingjiang sequence.

\section{Conclusions}

Through the addition of the arrival times from our temporary network, the present study has significantly improved our understanding about the source parameters of the 2011 Yingjiang sequence from the Yunnan observational bulletins. Our results show a clear seismicity zone along the ENE direction and an upside-down bowl-shaped structure in depth. After the Yingjiang mainshock, some earthquakes occurred along a SSE direction. These observations may suggest that the process of conjugate rupturing of the causative fault system of the Yingjiang mainshock is the principal cause of generating a number of aftershocks in two different directions. One is the ENE trending Da Yingjiang fault, while the other is a SSE trending blind fault. This may explain why a moderate-size Yingjiang earthquake has caused significant seismic hazards in the region.

Acknowledgements We thank Dr. F. Waldhauser for providing the location code used in this study, Earthquake Administration of Yunnan Province for the field work and observational bulletins, and Drs. L. Li and X. Li in Geophysical Exploration Center, CEA for guiding us to use the field equipment. This work was partially supported by National Natural Science Foundation of China (Nos. 40974201 and 40774044) to J. Lei. All of the figures were plotted by using GMT (Wessel and Smith, 1995).

\section{References}

China Earthquake Administration (2005). Catalogue of Chinese Strong Earthquakes. 1-100 (in Chinese).

Deng Q, Zhang P, Ran Y, Yang X, Min W and Chu Q (2002). Basic characteristics of active tectonics in China. Science in China (Series D) 32(12): 1 020-1 030.

Engdahl R, van der Hilst R and Buland R (1998). Global teleseismic earthquake relocation with improved travel times and procedures for depth determination. Bull Seismol Soc Am 88: 722-743.

Fang L, Wu J, Zhang T, Huang J, Wang C and Yang T (2011). Relocation of mainshock and aftershocks of the 2011 Yingjiang $M_{\mathrm{S}} 5.8$ earthquake in Yunnan. Acta Seismologica Sinica 33(2): 262-267 (in Chinese with English abstract).

Hu H, Lu H, Wang C, He Z, Zhu L, Yan Q, Fan Y, Zhang G and Deng Y (1986). The crustal structure in western Yunnan from man-made blasts. Acta Geophysica Sinica 29(2): 133-144.

Lei J, Xie F, Mishra O P, Lu Y, Zhang G and Li Y (2012). The 2011 Yingjiang, China, earthquake: A volcanorelated fluid-driven earthquake? Bull Seismol Soc Am 102: $417-425$.

Lei J, Zhao D and Su Y (2009). Insight into the origin of the Tengchong intraplate volcano and seismotectonics in southwest China from local and teleseismic data. $J$ Geophys Res 114: B05302.

Li L, Chen Q, Cheng X and Niu F (2007). Spatial clustering and repeating of seismic events observed along the 1976 Tangshan fault, North China. Geophys Res Lett 34: L23309.

Mishra O P, Zhao D and Wang Z (2008). The genesis of the 2001 Bhuj, India earthquake $\left(M_{\mathrm{W}} 7.6\right)$ : A puzzle for peninsular India? Indian Minerals 61(3-4)-62(1-4): 149-170.

Tapponnier P, Lacassin R, Leloup P, Scharer U, Zhong D, Wu H, Liu X, Ji S, Zhang L and Zhong J (1990). The Ailao Shan/Red-River metamorphic belt: Tertiary leftlateral shear between Indochina and South China. $\mathrm{Na}$ ture 343: 431-437.

Waldhauser F and Ellsworth W L (2000). A doubledifference earthquake location algorithm: Method and application to the north Hayward fault. Bull Seismol Soc Am 90: 1 353-1 368.

Wang C and Huangfu G (2004). Crustal structure in Tengchong volcano-geothermal area, western Yunnan, China. Tectonophysics 380: 69-87. 
Wang C, Zhu L, Lou H, Huang B, Yao Z and Luo X (2010). Crustal thickness and Poisson's ratios in the eastern Tibetan Plateau and their tectonic implications. J Geophys Res 115: B11301.

Wang E and Burchfiel B (1997). Interpretation of Cenozoic tectonics in the right-lateral accommodation zone between the Ailao Shan shear zone and the eastern Himalayan syntaxis. Inter Geol Rev 39: 191-219.

Wessel P and Smith W (1995). New version of the Generic Mapping Tools (GMT) version 3.0 released. EOS Trans $A G U$ 76: 329.

Yang Z X, Chen Y T, Zheng Y J and Yu X W (2003). Application of the double-difference earthquake location algorithm to the earthquakes in central and western China. Science in China (Series D) 33(Suppl.): 129-134.

Yin A and Harrison T (2000). Geological evolution of the Himalayan-Tibetan orogen. Ann Rev Earth Planet Sci 28: $211-280$.

Yu X W, Zhang H and Chen Y T (2010). Relocation of the earthquakes in northern China. J Geodesy Geodynamics
30(2): 29-33.

Zhang G (2010). Precise Relocation of Small Earthquakes Occurred in Northern China and Its Tectonic Implications. [Master Dissertation]. Institute of Crustal Dynamics, China Earthquake Administration, Beijing, 1-64 (in Chinese with English abstract).

Zhang G, Lei J, Xie F, Guo Y and Lan C (2011). Precise relocation of small earthquakes occurred in North China and its tectonic implication. Acta Seismologica Sinica 33(6): 699-714 (in Chinese with English abstract).

Zhang Z, Bai Z, Wang C, Lü Q, Teng J, Li J, Sun S and Wang X (2005). The crustal structure under Gondwona and Yangtze blocks: A wide-angle reflection from Menglian to Malong in western Yunnan. Science in China (Series D) 35(5): 387-392.

Zhao C, Hua R and Chen K (2006). Present-day magma chambers in Tengchong volcano area inferred from relative geothermal gradient. Acta Petrol Sin 22(6): 1 5171528 . 